\title{
Phase Analysis and Crystallographic Orientation of High Chromium Cast Iron Grain Using EBSD Technique
}

\author{
Dorota Siekaniec $^{\text {a* }}$, Dariusz Kopyciński ${ }^{\mathrm{a}}$

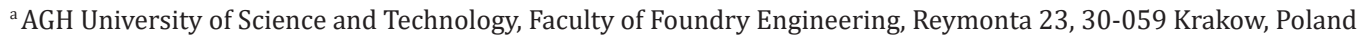 \\ *e-mail: dsiek@agh.edu.pl
}

Received: 21 November 2016/Accepted: 6 January 2017/Published online: 17 March 2017

This article is published with open access at AGH University of Science and Technology Press

\begin{abstract}
Grain orientation, properties, microstructure borders, and types and sizes of phases have had a major impact on the traits of modern engineering materials. Therefore, it is important to study, analyze, and (further) control the method of crystallizing alloys. One of the methods used to assess the orientation of grain growth is the EBSD technique. EBSD (Electron Backscatter Diffraction Analysis) enables us to perform quantitative analyses on the microstructure of materials (on a scale of millimetres to nanometres) in a scanning electron microscope. Using the EBSD technique can help us gain valuable information about the following properties of crystalline materials: crystal orientation, disorientation, grain boundaries, global and local texture, fractions recrystallization/deformation, stress analysis, characterization of intergranular boundaries, identification of phases, phase distribution, and so on. In this paper, we present the results of phase analysis and crystallographic orientation of the grains of high chromium cast iron via EBSD. These were preliminary studies to determine the possibility of using the EBSD technique for analyzing high chromium cast iron. Castings were produced under industrial conditions, then samples were cut out and testing using the EBSD technique. This method proved to be effective for this type of material.
\end{abstract}

\section{Keywords:}

microstructure, crystal orientation, EBSD technique, high chromium cast iron, grain

\section{INTRODUCTION}

The base of the EBSD method is a focused electron beam interacting with the sample at an inclination of $70^{\circ}$ to the optical axis of the microscope. A diagram of the EBS system is shown in Figure 1 [1-5].

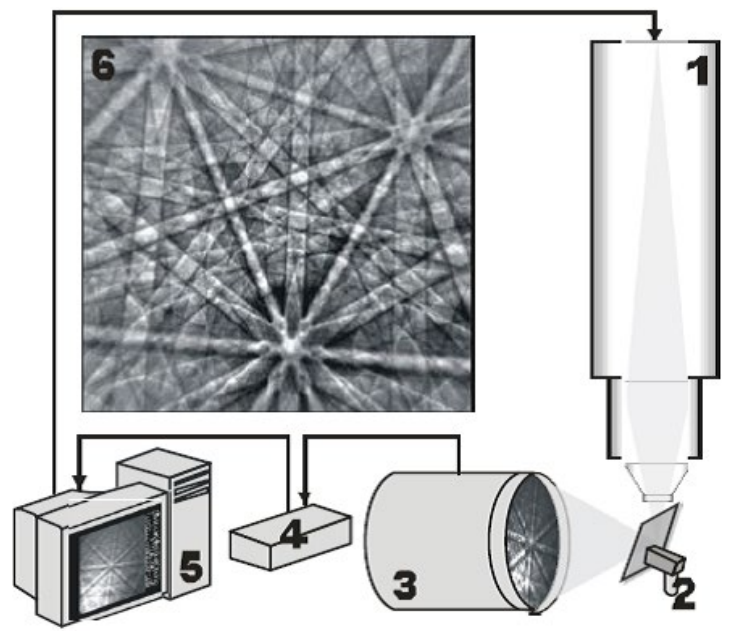

Fig. 1. EBSD technique: 1 - electron optical column; 2 - specimen, 3 - CCD camera; 4 - camera driver; 5 - computer controlling beam and performing image analysis; 6 - diffraction pattern [2]
Electrons penetrating the small depth of the sample surface are back-scattering and diffraction crystallographic planes. This phenomenon occurs at a distance of not more than $50 \mathrm{~nm}$ below the surface of the sample; hence, a high demand of the quality of the surface layer of the sample is required. The electrons are diffracted according to the Bragg's law and form two characteristic scattering cones (Kossel cones). These cones intersect the plane of the screen covered with a layer of phosphor and a CCD camera. They can be seen as a system of bands called Kikuchi lines (or Kikuchi patterns) (Fig. 2). The dilation angle of the Kossel cones are close to $180^{\circ}$; therefore, Kikuchi lines are sets of pairs of nearly parallel lines. Kikuchi lines are specific to the system and crystallographic orientation, which implies utility of this method in the study of the crystallographic orientation of the grains. Assigning each orientation grain a certain color can result in an image area of the microstructure as an orientation map [6-8].

The identification of phase components is performed by comparing the Kikuchi line registered on the samples of patterns generated by the application program EBSD detector on the basis of part of the database approved and specified by the operator. Each database is a collection of information about the characteristics and 
parameters of the structure of the different components of the phase, including the space group, a group of Laue diffraction, crystallographic system, lattice constants of the unit cell [1-9].

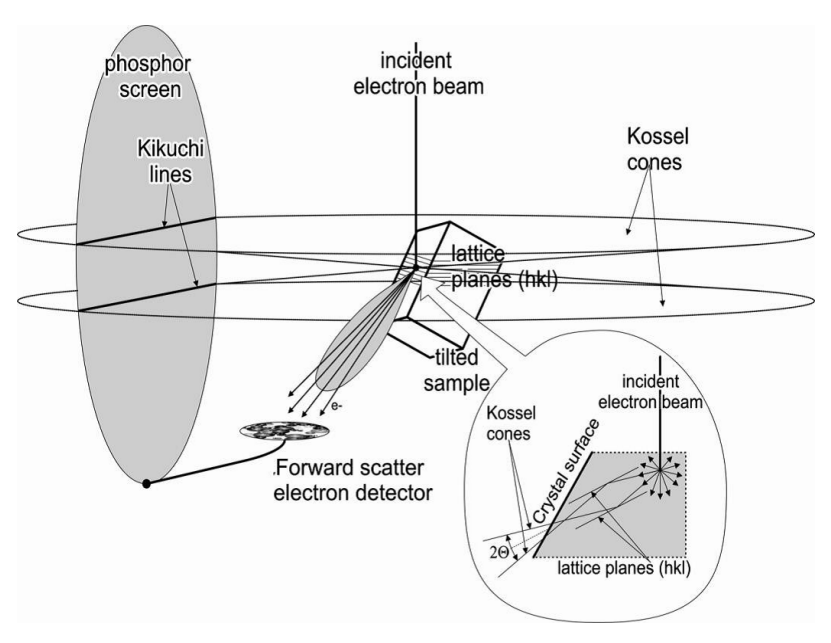

Fig. 2. Scheme of EBSD technique [2]

The advantages of using the EDSB technique undeniably allows for the greatest speed and reliability of determining the properties of the crystal lattice, orientation, and structure of the crystalline phases. Unlike optical techniques, it is possible to obtain information of all phases (even isotropic) and the opaque phase in this method. One of the major limitations in the application of EBSD is the stringent requirements of the prepared samples. EBSD measurement is made at a very short depth into the sample, whereby samples must be free of damage to the crystal lattice on the surface. Conventional grinding and polishing of samples for optical microscope results in significant damage to the crystal lattice near the surface of many types of materials; therefore, after the traditional polishing, it is necessary to perform additional chemical polishing It is a laborious and time-consuming process that requires experience with a variety of materials for obtaining the best results [3].

a)

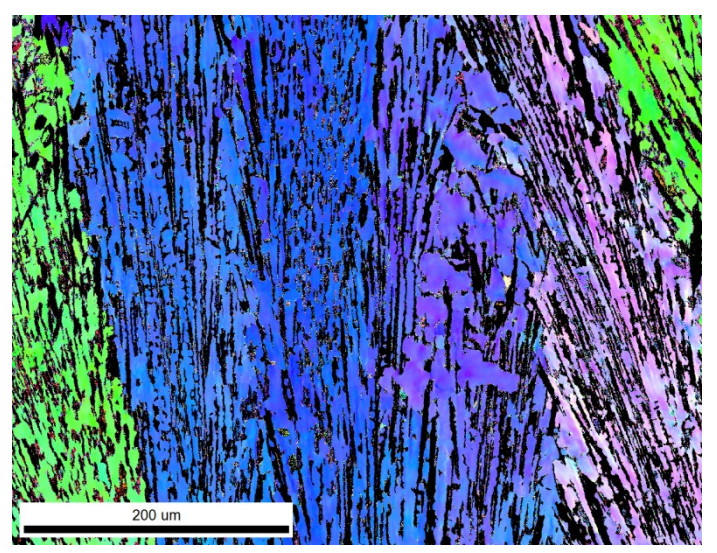

\section{METHODOLOGY}

The presented investigation focuses on the study of the microstructure on a sample of high chromium cast iron using the EBSD technique. The sample for testing was cut from a cast made of high chromium cast iron with the chemical composition shown in Table 1. The sample was prepared and tested at the Institute of Metallurgy and Materials Science Polish Academy of Sciences using an FEI Quanta 3D FEGSEM high-resolution scanning electron microscope with an additional column ion FIB integrated with an EDAX Trident (spectrometer EDAX Genesis spectrometer WDS Genesis LambdaSpec and system acquisition electron backscatter diffraction EBSD Genesis TSL).

Table 1

Chemical composition, wt. \%

\begin{tabular}{cccccccccc}
\hline $\mathrm{Fe}$ & $\mathrm{C}$ & $\mathrm{Si}$ & $\mathrm{Mn}$ & $\mathrm{P}$ & $\mathrm{S}$ & $\mathrm{Cr}$ & $\mathrm{Mo}$ & $\mathrm{Ni}$ & $\mathrm{Cu}$ \\
\hline 71 & 3.23 & 0.519 & 0.646 & 0.0384 & 0.0259 & 23.8 & 0.119 & 0.34 & 0.108
\end{tabular}

\section{RESULTS AND DISCUSSION}

The simplest way to generate an orientation map is by plotting the three Euler angles using an RGB color scheme; this is often referred to as a Euler map. The Euler colored maps provide a basic presentation of the microstructure; however there are limitations to these maps. One of these issues is that small orientation changes don't always correspond to small changes on the color scale, which can cause confusion when looking at a Euler map. To accommodate these issues, a different type of map display is often used.

The Inverse Pole Figure (IPF) color scheme uses a different presentation that is much easier to interpret and that doesn't normally show large color deviations when there are small changes in orientation. The color scheme is designed by assigning a color to each of the corners of the inverse pole figure. For each map, a reference sample direction (like the rolling direction) is chosen, and a color is assigned based on the measured crystal orientation and chosen viewing direction [3].

b)

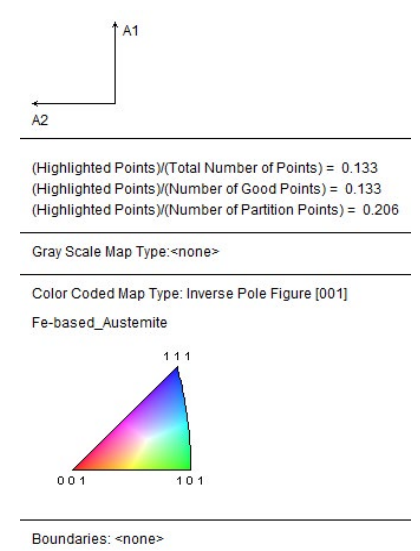

Fig. 3. An IPF crystallographic orientation map of: a) eutectic grains; b) the crystal reference frame 
Figure 3 presents the IPF orientation map of eutectic grains. From Figure 3, it can be found that the largest grain is oriented towards the crystallographic direction [111].

In the unique grain color map, each grain is shaded with a random color. In EBSD, a grain is defined to be bounded by a continuous high-angle boundary (boundary with a misorientation $>15^{\circ}$ ). This map is useful for distinguishing grains from one another, and the colors used in the unique grain color map do not correspond to the lattice orientation in any way [9].

Figure 4 a shows the unique grain color map of the sample. Figure $4 \mathrm{~b}$ presents the corresponding distributions of the misorientation angle of the eutectic grains. The misorientation angle distributions are characterized by a sharp peak near $2^{\circ}$ and then has the appearance of a normal distribution (from 15 to $65^{\circ}$ ).

In addition to the map of the microstructure, the EBSD analysis also gives information about the microstructure such as the number of grains and their average diameter as well as the selected information provided in Table 2 regarding the eutectic grains. Grain size is an important characteristic used to understand the development, engineering, and potential failure traits of iron and steels. EBSD is an ideal technique for determining grain size; it offers microstructural characterization including grain boundary characterization, and texture quantification.

Table 2

Summary information about eutectic grains

\begin{tabular}{cc}
\hline $\begin{array}{c}\text { Grain Size } \\
\text { (Excluding Edge Grains) }\end{array}$ \\
\hline Number of Grains & 6069 \\
\hline Number of Edge Grains & 172 \\
\hline Average Diameter & $1.63(1.39)$ microns \\
\hline Equivalent Area & $2.08(1.52)$ square microns \\
\hline Equivalent ASTM No & $15.9(16.4)$ \\
\hline
\end{tabular}

EBSD analysis can distinguish groups of the selected grains and analyze them. Figure 5 shows an analysis aimed at determining the diameter of the grains that occupy most of area fraction of the sample. The biggest area fraction (0.227265) occupies just one, the largest grain of a size diameter equal to $163.525 \mu \mathrm{m}$. a)

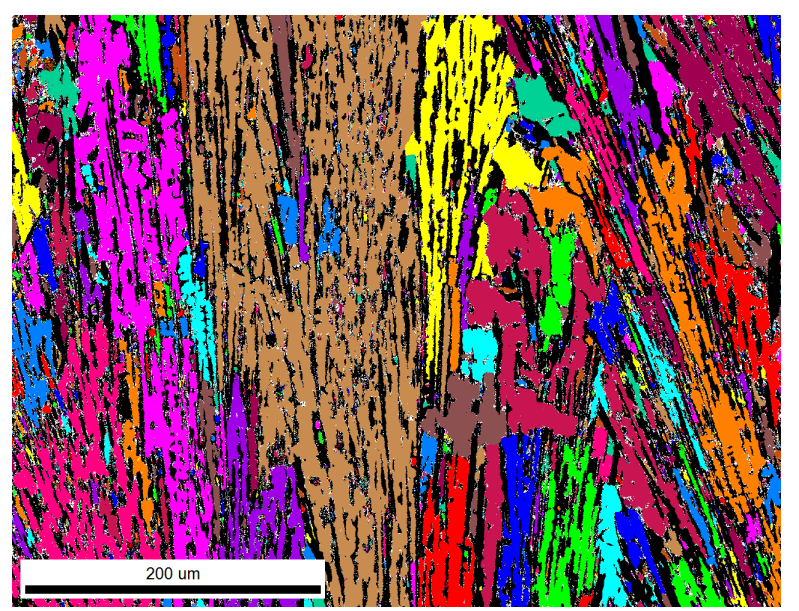

b)

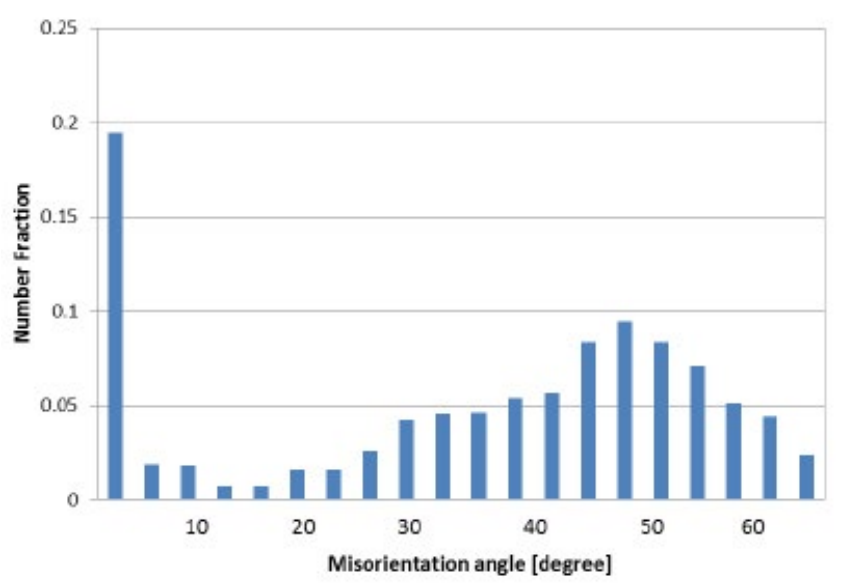

Fig. 4. Unique grain color map (a); the corresponding area fraction as a function of misorientation angles showing relationships between grains (b)

a)

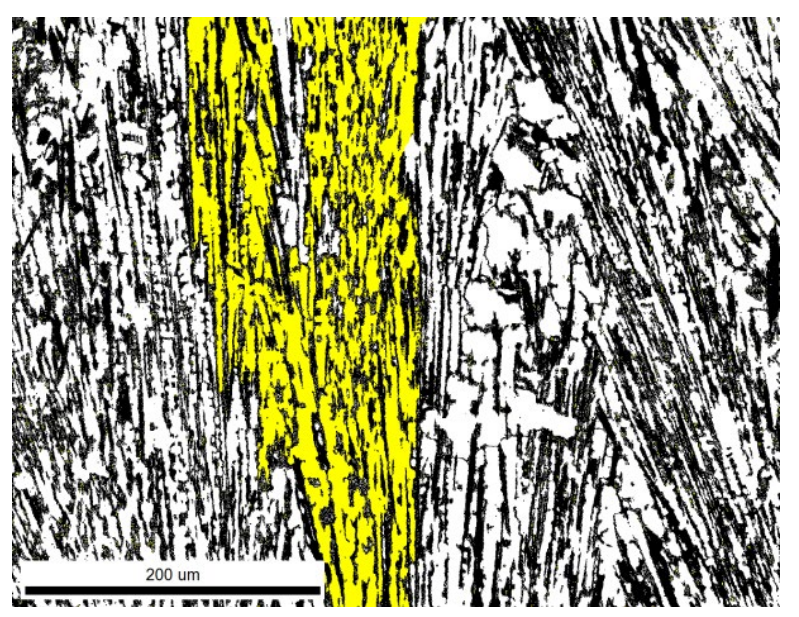

b)

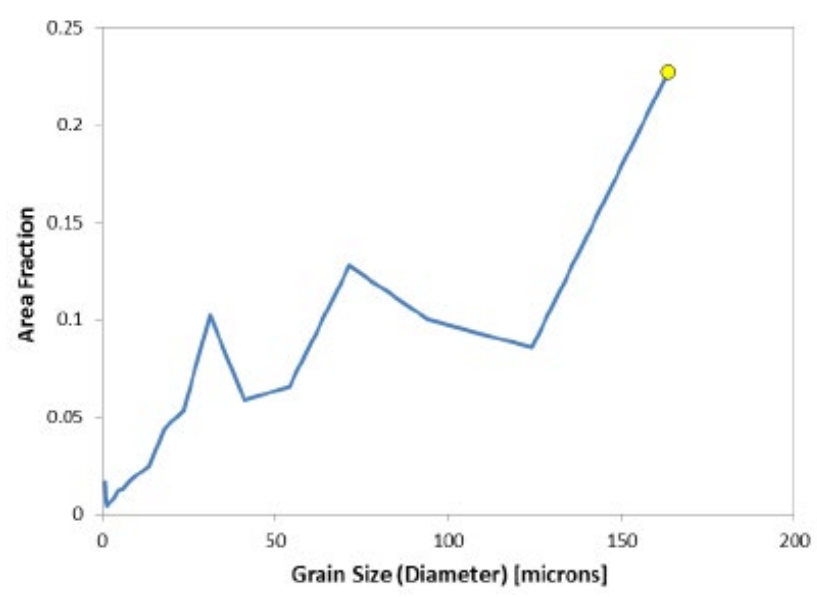

Fig. 5. Map of the biggest eutectic grain (a); graph of grain size diameter of area fraction (b) 
The second-most-often grains growing are that with diameters of approx. 70 microns and an occupied area fraction of 0.127 (Fig. 6 - in red).

EBSD is applied to identify the major and minor phases within a material. This can include the identification of intermetallic phases, secondary phases and precipitates within a processed material, and the identification of mineral assemblages in naturally occurring material. In addition to identifying an unknown phase, another benefit of EBSD is to visualize the spatial distribution of these phases. This can be very important, for example, when investigating the occurrence of secondary phases either at the grain boundaries or within the grains themselves. Typically, EBSD can differentiate between different crystallographic phases, and EDS can show the chemical composition. When the results from these two systems are combined using a sophisticated analysis system, it is possible to use these tools to identify and separate any unknown phases or compounds [4].

Figure 7 shows the phase map of the sample. It can be seen that two phases occur - the Fe-based austenite phase and the Chromium Carbide phase. The Fe-based austenite phase occupies $65 \%$ of the area, whereas the carbide phase constitutes $35 \%$. It can be seen that the phases are distributed homogeneously.

\section{CONCLUSIONS}

Analysis using an EBSD system provides great opportunities to learn more about the material. It can determine the crystallographic orientation of the structure and examine the amount and distribution of phases. The EBSD method can analyze one phase or even a single grain. The EBSD system provides information about the size and angle of the misorientation selected crystals.

The presented investigation shows that two phases occur in this material - the Fe-based austenite phase (which occupies $65 \%$ of the area) and the Carbide phase (constituting 35\%). Using the EBSD technique determined the number of particles (6069 grains) and the average diameter of the grains (1.63 [1.39] microns). The experimental results indicate that EBSD analysis can be used to study high chromium cast iron.

b)

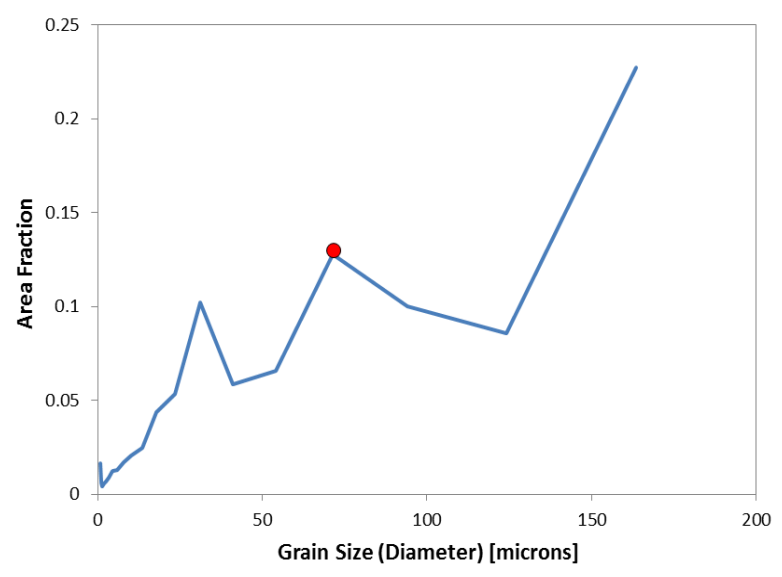

Fig. 6. Map of eutectic grains with diameters of approx. 70 microns (red) (a); graph of grain size diameter of area fraction (b)
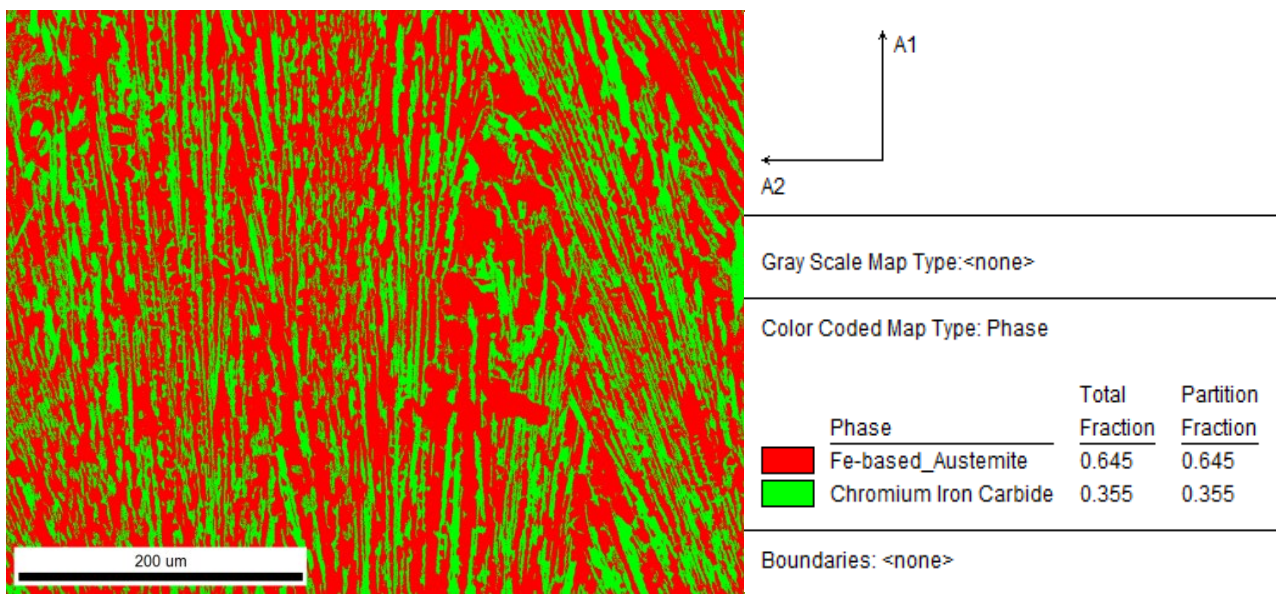

Gray Scale Map Type:<none>

Color Coded Map Type: Phase

\begin{tabular}{|c|c|c|}
\hline Phase & $\begin{array}{l}\text { Total } \\
\text { Fraction }\end{array}$ & $\begin{array}{l}\text { Partition } \\
\text { Fraction }\end{array}$ \\
\hline$\overline{\text { Fe-based_Austemite }}$ & $\overline{0.645}$ & $\overline{0.645}$ \\
\hline Chromium Iron Carbide & 0.355 & 0.355 \\
\hline
\end{tabular}

Boundaries: <none>

Fig. 7. Phase map with legend 


\section{Acknowledgements}

The study was co-financed by NCBiR as a targeted project No. PBS/B5/44/2015.

\section{REFERENCES}

[1] Faryna M. (2012). Dyfrakcja elektronów wstecznie rozproszonych $w$ skaningowym mikroskopie elektronowym. Kraków: Wydawnictwa AGH.

[2] Dyfrakcja elektronów wstecznie rozproszonych. Retrieved from http://www.imim.pl/files/Wyklad\%20V.pdf (accessed 07.11.2016).

[3] Explained EBSD From data acquisition to advanced analysis. Retrieved from https://www.oxford-instruments.com/ products /microanalysis/ebsd (accessed 07.11.2016).

[4] Phase Identification and Separation in SEM. Retrieved from https://www.oxford-instruments.com/products/ microanalysis/ebsd (accessed 07.11.2016).
[5] Kang J.S., Seol J.-B. \& Park C.G. (2013). Three-dimensional characterization of bainitic microstructures in low-carbon high-strength low-alloy steel studied by electron backscatter diffraction. Material Characterisation, 79, 110-121. doi: 10.1016/j.matchar.2013.02.009

[6] Unnikrishnana R., Idury K.S.N.S., Ismail T.P; Bhadauria A., Shekhawat S.K., Khatirkar R.K. \& Sapate S.G.(2014). Effect of heat input on the microstructure, residual stresses and corrosion resistance of $304 \mathrm{~L}$ austenitic stainless steel weldments. Material Characterisation, 93, 10-23. doi: 10.1016/j.matchar. 2014.03.013

[7] Sozańska M, Chmiela B. (2012). Ocena możliwości stosowania metody EBSD w badaniach mikrostruktury stopów tytanu. Inżynieria Materiałowa, 4, 311-314.

[8] Maitland T. \& Sitzman S. (2007). Backscattering Detector and EBSD in Nanomaterials Characterization. New York: Springer.

[9] Kamp A. (2007). Investigation of Titanium $\alpha$ Plates by EBSD Analysis. Master thesis. Delft University of Technology, Delf, Netherlands. 